\title{
Histopathology of Polyps and Cancer of Colorectum: A ten years study from a tertiary care center in Nepal
}

\author{
Binita Goyal*
}

\author{
Department of Pathology, College of Medical Sciences, Bharatpur, Chitwan, Nepal
}

\begin{abstract}
Introduction: Polyps and colorectal cancer have overlapping clinical presentation and may be difficult to diagnose on clinical grounds alone and close clinicopathological correlation is required for correct diagnosis and management. This study was aimed to see the spectrum of polyps and cancer in colorectum, see the percentage of colorectal cancer in younger individuals, see association between histologic grade and pathologic stage at presentation and compare site of tumor and pathologic stage at presentation in younger and older age group. Methods: This study was carried out on 138 consecutive cases of polyps and malignant lesions of colorectum during a time period of 10 years from January 2011 to December 2020. Results: Age of the patients ranged from 2 to 90 years with mean 45.1 years and a male female ratio 2:1. There were $58(42.0 \%)$ cases of polyps and 80 (58.0\%) cases of malignancies. 37 (46.3\%) malignancy cases were seen in individuals $\leq 50$ years of age. Most common site of involvement was rectum in 80 (58.0\%) cases. Most common non-neoplastic polyp was retention polyp comprising 25 (67.6\%) and most common neoplastic polyp was adenoma comprising of 18 (85.7\%) cases. Most common malignancy was adenocarcinoma comprising 75 (93.8\%) cases. Conclusions: Significant number of malignancies is seen in younger individuals stressing the need for suspicion and surveillance in this age group. Histologic grade is an important prognostic parameter and there is no difference in site of tumor and stage at presentation between younger and older age group.
\end{abstract}

Keywords: Adenoma, colorectal, colorectal carcinoma, juvenile retention polyp, polyp.

\section{*Correspondence:}

Dr. Binita Goyal

Assistant Professor

Department of Pathology

College of Medical Sciences, Bharatpur, Chitwan, Nepal

Email: binitagoyal@yahoo.com

Submitted: August 2, 2021

Accepted: September 20, 2021

To cite: Goyal B. Histopathology of Polyps and Cancer of Colorectum: A ten years study from a tertiary care center in Nepal. JGMC Nepal. 2021;14(2):100-6.

DOI: $10.3126 /$ jgmcn.v14i2.38385

\section{INTRODUCTION}

Large bowel is the terminal portion of gastrointestinal tract (GIT) in most of the vertebrates and is truly distinct only in tetrapods where it is separated from the small intestine by a distinct ileocecal valve. ${ }^{1}$ Spectrum of colorectal diseases spans from infectious diseases to inflammatory, idiopathic, motility disorders and neoplastic lesions comprising both benign and malignant conditions and tumor like lesions. ${ }^{2,3}$ The severity of these conditions can vary from mild irritating to as severe as life threatening. Early screening and effective management of colorectal diseases can significantly improve treatment outcomes and survival rates. ${ }^{4}$

Polyp is a macroscopically visible projection above a mucosal surface. These are most commonly present in colorectal region, though any part of GIT may be involved. Intestinal polyps can be classified as neoplastic and non-neoplastic in nature. Non-neoplastic type can be further classified into hyperplastic, inflammatory and hamartomatous types. Any neoplastic lesion like adenocarcinoma, lymphoma, stromal tumors, carcinoid tumors or metastases from other sites can form a polyp. However, the most common type of neoplastic polyp is adenoma which is precursor of majority of colorectal 
adenocarcinoma. Adenoma is a benign intraepithelial neoplasm characterized by presence of dysplasia. ${ }^{5}$

Colorectal cancer (CRC) is the most common malignancy of GIT and is a major cause of morbidity and mortality worldwide. ${ }^{5}$ According to Global Cancer Statistics, 2020, colorectal cancer is the third most common incidence wise and second most common mortality wise in both males and females. ${ }^{6}$ However, in Nepal, it is the eighth most common incidence wise and tenth most common mortality wise. ${ }^{7}$ It is most commonly seen in sixth to seventh decade. ${ }^{5}$ However, incidence and mortality due to CRC is increasing in young individuals because screening is limited in them and key symptoms may go unrecognized. ${ }^{8}$ Flexible colonoscopy has revolutionized the clinical management of colonic diseases including early detection and treatment of CRC. Colonoscopy along with mucosal biopsy is the gold standard as invasive cancer may be present in even small polyps ( 6 to $9 \mathrm{~mm})^{7,9}$

This study was aimed to see the spectrum of polyps and cancer in colorectum, see the percentage of colorectal cancer in younger individuals, see association between histologic grade and pathologic stage at presentation and compare site of tumor and pathologic stage at presentation in younger and older age group.

\section{METHODS}

This retrospective chart review was carried out in Department of Pathology, College of Medical Sciences and Teaching Hospital. Ethical approval from the Institutional Review Committee was obtained (Reference no. COMSTHIRC/2021-42). One hundred and thirty-eight consecutive cases of polyps and malignant lesions of colorectum received in colonoscopic biopsy and resected specimens in the Histopathology section of Department of Pathology of College of Medical Sciences and Teaching Hospital during a time period of 10 years from January 2011 to December 2020 were included in the study. Insufficient biopsies including only mucosa or part of mucosa, recurrent tumors, tumors of appendix and anal canal were excluded. Malignancies were classified and staged according to World Health Organization Classification of Tumors (fourth edition). ${ }^{10}$ Histologic grading was done as well, moderately, poorly and undifferentiated. ${ }^{11}$ Cases $\leq 50$ years of age were considered younger age group. Cecum, ascending colon and transverse colon were considered as proximal colon and descending colon, sigmoid and rectum were considered as distal colon. All the cases of polyps and malignant lesions received in the study period were reviewed from the departmental records. Data was initially entered in microsoft excel sheet, refined and finally analyzed by Statistical Packages for Social Sciences version 20.0. Variables like age at presentation, gender, site, gross type, histological type, differentiation and extent of tumor invasion were analyzed. Continuous variables were expressed as mean \pm standard deviation (S.D.) and categorical variables were expressed as frequencies and percentages. Association between histologic grade and pathologic stage and site of tumor and pathologic stage were compared in younger and older age group, both, were sought using Likelihood ratio and level of significance was considered at 95\% confidence interval.

\section{RESULTS}

Altogether 138 cases of polyps and malignant lesions were received in the study. Age of the patients ranged from 2 to 90 years with mean \pm S.D. of $45.1 \pm 21.2$ years with maximum $26(18.8 \%)$ cases in 51 to 60 years age group. There were 92 (66.7\%) males and 46 (33.3\%) females with a male female ratio 2:1. There were $58(42.0 \%)$ cases of polyps and $80(58.0 \%)$ cases of malignancies. Maximum 14 $(24.1 \%)$ cases of polyps were seen in $<10$ years age group and maximum $20(25.0 \%)$ cases of malignancies were seen in 51 to 60 years age group. 37 (46.3\%) malignancy cases were seen in younger individuals $\leq 50$ years of age (Figure 1).

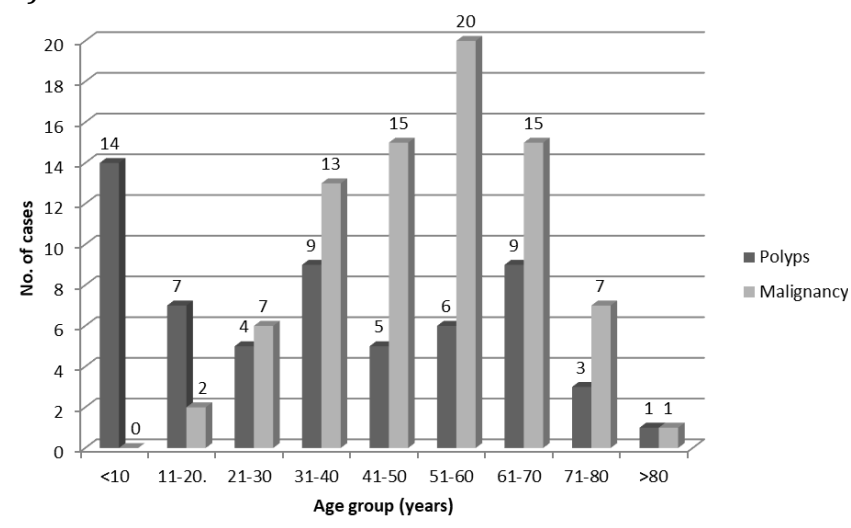

Figure 1: Bar diagram showing age distribution of polyps and malignant cases $(\mathrm{N}=138)$

Out of 58 cases of polyps, 37 (63.8\%) cases were nonneoplastic and 21 (36.2\%) cases were neoplastic. Out of 37 cases of non-neoplastic polyp, most common was retention polyp comprising 25 (67.6\%) cases and out of 21 cases of neoplastic polyp, most common was adenoma comprising 
of $18(85.7 \%)$ cases. Out of 80 cases of malignancy, most common was adenocarcinoma comprising 75 (93.8\%) cases (Table 1). Six (8.0\%) cases of adenocarcinoma were mucinous and two (2.7\%) cases were signet ring cell carcinoma. Five $(83.3 \%)$ cases of mucinous adenocarcinoma were seen in younger age group.

Table 1: Histological diagnosis $(\mathrm{N}=138)$

\begin{tabular}{llc}
\hline S.N & Histological diagnosis & Number (\%) \\
\multicolumn{2}{l}{ Non-neoplastic polyps (n= 37) } & \\
1 & Retention polyp & $25(67.6)$ \\
2 & Inflammatory polyp & $10(27.0)$ \\
3 & Hyperplastic polyp & $2(5.4)$ \\
Neoplastic polyps (n = 21) & \\
1 & Tubular adenoma & $13(61.9)$ \\
2 & Tubulovillous adenoma & $4(19.0)$ \\
3 & Villous adenoma & $1(4.8)$ \\
4 & Lipoma & $3(14.3)$ \\
Malignancy (n = 80) & \\
1 & Adenocarcinoma & $75(93.8)$ \\
2 & Non-Hodgkin's lymphoma (NHL) & $3(3.6)$ \\
3 & Gastrointestinal stromal tumor (GIST) & $1(1.3)$ \\
4 & Secondary metastases & $1(1.3)$ \\
\hline
\end{tabular}

Most common site of involvement was rectum in 80 $(58.0 \%)$ cases for both polyps and malignancy (Figure 2 ).

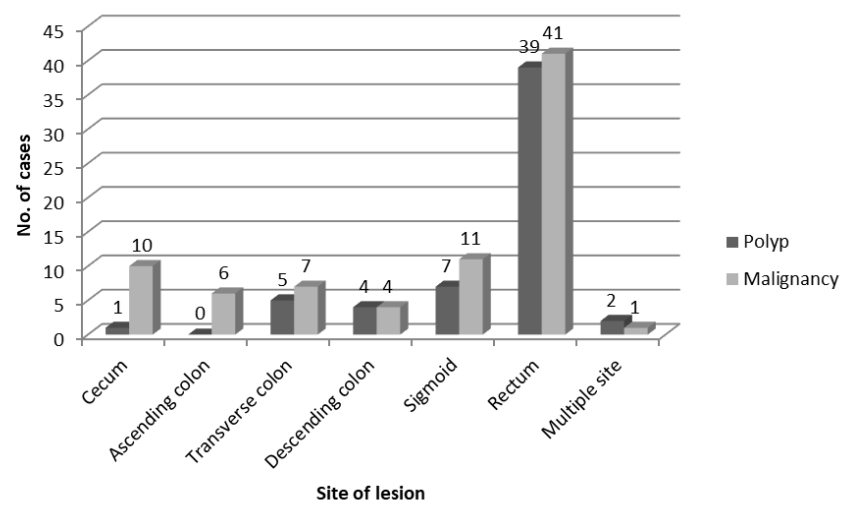

Figure 2: Bar diagram showing site distribution of polyps and malignancy $(\mathrm{N}=138)$

Majority, 50 (86.2\%) cases of polyps were solitary, six $(10.3 \%)$ cases were two in number and two (3.5\%) cases were multiple. Seventy-nine (98.8\%) cases of malignancy were solitary and only one $(1.2 \%)$ case had two synchronous primary tumors in cecum and sigmoid colon. Size of the polyps ranged from 0.2 to $6.5 \mathrm{~cm}$ with mean \pm S.D. of $1.3 \pm 1.2 \mathrm{~cm}$.

Malignancy was diagnosed in 59 (73.7\%) resected specimens and 21 (26.3\%) colonoscopy biopsies. In the resected tumors, size of the tumors ranged from 1.5 to 14.0 cm with mean \pm S.D. of $5.8 \pm 2.5 \mathrm{~cm}$. Fifty-four (91.5\%) cases out of 59 resected specimens were adenocarcinoma. One
$(1.7 \%)$ case in a 36 years old male had two synchronous primary tumors in cecum and sigmoid colon. Tumor in sigmoid colon was well differentiated adenocarcinoma and that in cecum was mucinous adenocarcinoma. Out of remaining 53 cases, 26 (49.1\%) tumors were annular growths, 19 (35.8\%) were exophytic masses and 8 (15.1\%) were ulcerated growths. Twenty two out of 26 (84.6\%) annular growths were seen in distal colon.

Out of 53 cases, $24(45.3 \%)$ cases of adenocarcinoma were well differentiated. 31 (58.5\%) cases were pathologic stage III tumors. There was significant association between histologic grade and pathologic stage $(\mathrm{P}<0.05)$ (Table 2$)$.

Table 2: Histologic grade and pathologic stage at presentation of adenocarcinoma $(n=53)$

\begin{tabular}{lcccc}
\hline $\begin{array}{l}\text { Pathologic } \\
\text { stage }\end{array}$ & $\begin{array}{c}\text { Well } \\
\text { differentiated } \\
\mathbf{n}(\%)\end{array}$ & $\begin{array}{c}\text { Histologic grade } \\
\text { Moderately } \\
\text { differentiated } \\
\mathbf{n}(\%)\end{array}$ & $\begin{array}{c}\text { Poorly } \\
\text { differentiated } \\
\mathbf{n}(\%)\end{array}$ & $\begin{array}{c}\text { Total } \\
\mathbf{n}(\%)\end{array}$ \\
Stage I & $8(15.1)$ & $2(3.8)$ & $0(0)$ & $\begin{array}{c}10 \\
(18.9)\end{array}$ \\
Stage II & $4(7.5)$ & $6(11.3)$ & $1(1.9)$ & $\begin{array}{c}11 \\
(20.8)\end{array}$ \\
Stage III & $12(22.6)$ & $11(20.8)$ & $8(15.1)$ & 31 \\
Stage IV & $0(0)$ & $0(0)$ & $1(1.9)$ & $1(1.9)$ \\
Total & $24(45.3)$ & $19(35.8)$ & $10(18.9)$ & $53(100)$ \\
Likelihood ratio $=12.949, \mathrm{p}=0.044$ & & & \\
\hline \multicolumn{5}{l}{} \\
\end{tabular}

Twenty six out of 53 resected cases of adenocarcinoma were seen in younger individuals. Out of these 26 cases, 17 $(65.4 \%)$ cases were stage III tumors at presentation and $11(42.3 \%)$ cases were located in proximal colon. However, when compared with older age group, these two findings were not statistically significant $(\mathrm{P}>0.05)$ (Table 3$)$.

Table 3: Comparison of site and pathologic stage in younger and older age group $(n=53)$

\begin{tabular}{lll}
\hline Site of tumor & Younger age group ( $\leq \mathbf{5 0}$ years) & Older age group ( $>\mathbf{5 0}$ years) \\
Proximal colon & $11(20.8)$ & $8(15.1)$ \\
Distal colon & $15(28.3)$ & $19(35.8)$ \\
Pearson Chi square $(\boldsymbol{2}) \mathbf{= 0 . 9 2 6}, \mathbf{P}=\mathbf{0 . 3 9 8}$ & \\
Pathologic & Younger age group ( $\leq \mathbf{5 0}$ years) & Older age group ( $>\mathbf{5 0}$ years) \\
stage & & $7(13.2)$ \\
Stage I & $3(5.7)$ & $6(11.3)$ \\
Stage II & $5(9.4)$ & $14(26.4)$ \\
Stage III & $17(32.1)$ & $0(0)$ \\
Stage IV & $1(1.9)$ & \\
Likelihood ratio $=3.395, \mathrm{P}=0.335$ &
\end{tabular}

\section{DISCUSSION}

A large proportion of human diseases are attributed to colon. Colon is the primary host for many neoplasms. ${ }^{2}$ 
Colorectal adenomas and cancer are common. Polyps and CRC may have overlapping clinical presentation and may be difficult to diagnose on clinical grounds alone and close clinicopathological correlation is required for correct diagnosis and management. ${ }^{3,12}$ CRC is a significant public health and surgical management issue. Surgical resection is still the mainstay of management and pathological examination of the resected specimen is the key to determining prognosis and guide for adjuvant oncologic therapy. ${ }^{12}$ Various gastrointestinal symptoms are frequent in Nepal and they are more commonly interpreted as noncancerous origin. Also easy availability of over the counter broad spectrum antibiotics lead to delay in seeking care. Hence, patients tend to land up at advanced stage. ${ }^{2}$

This study included 138 cases of polyps and malignancy of colorectum. Age of the patients ranged from 2 to 90 years with mean 45.1 years and maximum $18.8 \%$ cases in 51 to 60 years age group. Males were twice more commonly affected. These findings were similar to findings of Vaidya et al in Nepal who had 125 cases of tumor and tumor like lesions of colon and rectum where mean age was 38.4 years, maximum $18.4 \%$ cases were seen in 51 to 60 years age group and males were thrice more commonly affected. ${ }^{3}$

A polyp is simply an abnormal protrusion from mucosal surface. Adenoma is a benign neoplasm of colonic mucosa. Seldom symptomatic, they are of clinical concern as most of them are precursor for CRC. ${ }^{12}$ Classification of polyp is based on histological type which determines its malignant potential. Therefore, any polyp detected radiologically or endoscopically should be removed and its histological type and hence clinical behavior should be enlightened. ${ }^{13}$ In our study, $42 \%$ cases were polyps and $58.0 \%$ cases were malignancy. Retention polyp was the most common type of non-neoplastic polyp comprising $18.1 \%$ cases and tubular adenoma was the most common neoplastic polyp comprising $9.4 \%$ cases. In study conducted by Vaidya et $\mathrm{al}^{3}$, polyps comprised a much higher $71.2 \%$. However, in their study also, retention polyp was the most common non-neoplastic polyp and tubular adenoma was the most common neoplastic polyp comprising $27.2 \%$ and $19.2 \%$ cases respectively. ${ }^{3}$ However, in study conducted by Kefeli et al. ${ }^{13}$, adenomatous polyp was the most common followed by hyperplastic polyp comprising $44.3 \%$ and $37 \%$ cases respectively in their study on 192 polyps of large intestine. Retention polyp was not seen in their study which may be because the youngest patient was 21 years old and retention polyp is most commonly seen in children. ${ }^{5}$ Rectum was the most common site involved in $58.0 \%$ cases of both polyps and malignancy which was similar to finding of Vaidya et $\mathrm{al}^{3}$, where rectum was involved in $48.8 \%$ cases.

Malignancy comprised $58.0 \%$ of total cases. Age of the patients ranged from 16 to 88 years with mean \pm S.D. of $51.76 \pm 15.78$ years. These findings were similar to findings of Vaidya et al. ${ }^{3}$, Rajbhandari et al. $^{2}$ and Shah et al. ${ }^{14}$ where age ranged from 16 to 87 years and mean age was 51.80 , 52 and 53 years respectively. Males were more commonly affected than females with a male female ratio of 1.7:1. Males were more commonly affected also in studies conducted by Vaidya et al. ${ }^{3}$, Shrestha et al. ${ }^{15}$ and Ibrahim et al. ${ }^{16}$ with male female ratio of $3: 1,1.4: 1$ and 1.5:1 respectively. However, females were slightly more commonly affected in studies conducted by Shah et al. ${ }^{14}$ and Rajbhandari et al. ${ }^{2}$ with male female ratio of $0.9: 1$ and $1: 1.08$ respectively. $64.2 \%$ cases were seen in distal colon and $35.8 \%$ cases were seen in proximal colon which was similar to studies of Rajbhandari et al. ${ }^{2}$ and Vaidya et al. ${ }^{3} 51.3 \%$ cases of malignancy were seen in rectum. This was similar to finding of Shrestha et al. ${ }^{15}$ and Ibrahim et al. ${ }^{16}$ where rectum was involved in $50 \%$ and $60.2 \%$ cases respectively. Colon and rectum are continuous and both colon and rectal cancer are considered as same disease, however, rectal cancer has substantially greater risk of local recurrence due to its anatomical location. ${ }^{17}$

Adenocarcinoma was the most common malignancy seen in $93.8 \%$ cases and majority (45.3\%) were well differentiated. Several studies conducted by Vaidya et al. ${ }^{3}$, Shah et al. ${ }^{14}$, Kansakar et al. ${ }^{18}$ and Rawal et al. ${ }^{19}$ have also shown that adenocarcinoma was the most common malignancy, however, in their studies, moderately and poorly differentiated tumors were more common. In study conducted by Ibrahim et al. ${ }^{16}$, well differentiated carcinoma was most common comprising $52.3 \%$ cases which is in accordance with present study. Poorly differentiated tumors are found to be more proliferative and metastasize early in comparison to well differentiated tumors. ${ }^{20}$ Histologic grade is an important prognostic parameter in addition to stage in colorectal cancer. ${ }^{21}$ Present study observed a significant correlation between histologic grade and pathologic stage at presentation ( $\mathrm{p}<0.05) .58 .5 \%$ tumors were stage III in present study. Rawal et al had found a higher $35.8 \%$ stage I tumors as compared to $31.6 \%$ stage IIIF tumors. Stage I and II tumors are localized, Stage III tumors show regional lymph node involvement and Stage IV tumors show distant 
metastasis. ${ }^{18}$ Five year survival for CRC is $90 \%$ for patients with localized disease, $69 \%$ for regional spread and below $12 \%$ for distant metastasis. ${ }^{22}$

Mucinous subtype in adenocarcinoma was seen in $8.0 \%$ cases in presentstudy. Mucinous colorectal adenocarcinoma is found in $10 \%$ to $20 \%$ of CRC patients and occurs more commonly in younger patients. This histology is an adverse prognostic indicator. ${ }^{23}$ Similarly, signet ring cell carcinoma is also a rare histologic subtype of adenocarcinoma seen in less than $1 \%$ to $2.4 \%$ cases with adverse prognosis. ${ }^{24}$ There were two $(2.7 \%)$ cases of signet ring cell carcinoma in present study. Primary lymphomas of colon comprise < $10 \%$ of gastrointestinal lymphomas and are less common than gastric and small bowel lymphomas. ${ }^{10}$ There were three $(3.6 \%)$ cases of NHL in colon in present study. One case of colonic Gastrointestinal stromal tumor (GIST) was also seen in this study. Colonic GISTs are rare and comprise approximately $1 \%$ of all GISTs and are advanced tumors when detected and have a poor prognosis. ${ }^{10}$

Present study observed $46.3 \%$ cases of malignancy cases in $\leq 50$ years of age. Various studies conducted in Nepal by Shah et al. ${ }^{14}$ who observed $16.7 \%$ cases below 40 years of age, Shrestha et al. ${ }^{15}$ who observed $35.9 \%$ cases in less than 45 years age, Rajbhandari et al. ${ }^{2}$ and Rawal et al. ${ }^{18}$ who have respectively found $36 \%$ and $37 \%$ cases below 50 years of age have shown that CRC in young is also seen in quite a significant number of individuals. CRC in young as defined as CRC in less than 50 years of age is in increasing trend. ${ }^{25}$ Young patients tend to ignore symptoms and present at a late stage due to aggressive tumor biology and also because routine screening is done after 50 years of age. ${ }^{18}$ Some studies suggest that CRC in young have different clinical behavior than CRC in old and tend to be situated in distal colon and rectum, be more poorly differentiated, have mucinous or signet ring features and present at advanced stage. ${ }^{8,26}$ Distal colon though more commonly involved, proximal colon was also involved in $42.3 \%$ cases in present study. Kansakar et al. ${ }^{19}$ had observed a rise in incidence of right sided colon cancer in their study in young individuals. $26.9 \%$ cases were only poorly differentiated whereas $42.3 \%$ were moderately differentiated. Kansakar et al. ${ }^{19}$ had observed more than $50 \%$ cases as poorly differentiated. Five out of six cases of mucinous and one out two cases of signet ring cell adenocarcinoma were seen in younger age group. In the present study $65.4 \%$ cases presented as stage III tumors. However, present study did not observe any statistical significant difference in stage of presentation between young and old. Similarly, Poudyal et al. ${ }^{26}$ also did not observe significant difference in stage of presentation between young and old. According to Kansakar et al. ${ }^{19}$, they had observed a trend of comparatively early diagnosis than previous years.

\section{CONCLUSIONS}

Polyps and malignancy of colorectum are quite common. Juvenile retention polyp was the most common nonneoplastic polyp, tubular adenoma was most common neoplastic polyp and adenocarcinoma was the most common malignancy. A significant number of CRC cases are seen in younger individuals stressing the need for suspicion and surveillance in younger individuals also presenting with symptoms. Rectum was the most common site involved and there was significant association between histologic grade and pathologic stage at presentation.

CONFLICT OF INTEREST: None declared.

\section{SOURCE OF FUNDING: None}

\section{REFERENCES}

1. Fry RD, Mahmoud NN, Maron DJ, Bleier JIS. Colon and rectum. In: Townsend CM, editor. Sabiston text book of Surgery. 19th ed. Toronto: Elsevier; 2012. p.12941380. DOI: 10.1016/B978-1-4377-1560-6.00052-4

2. Rajbhandari M, Karmacharya A, Khanal K, Dhakal $P$, Shrestha R. Histomorphological Profile of Colonoscopic Biopsies and Pattern of Colorectal Carcinoma in Kavre District. Kathmandu Univ Med J. 2015;11:196-200. DOI: 10.3126/kumj.v11i3.12503 PMID: 24442164.

3. Vaidya P, Adhikari RC, Pant AD. Histopathologic analysis of tumor and tumor-like lesions of colon and rectum. JPN. 2020;10:1654-8. DOI: 10.3126/jpn.v10i1.28747

4. Zavoral M, Suchanek S, Majek O, Fric P, Minarikova $\mathrm{P}$, Minarik $\mathrm{M}$, et al. Colorectal cancer screening: 20 years of development and recent progress. World J Gastroenterol. 2014;20(14):3825-34. DOI: 10.3748/ wjg.v20.i14.3825 PMID: 24744575.

5. Turner JR. The gastrointestinal tract. In: Kumar V, Fausto N, Aster JC, Abbas AK, editors. Robbins and Cotran Pathologic basis of disease. 8th ed. Philadelphia: Elsevier; 2010. p.763-832. DOI: 10.1016/B978-14377-0792-2.50022-5 
6. Sung H, Ferlay J, Siegel RL, Laversanne M, Soerjomataram I, Jemal A, et al. Global Cancer Statistics 2020: GLOBOCAN Estimates of Incidence and Mortality Worldwide for 36 Cancers in 185 Countries. CA Cancer J Clin. 2021;71(3):209-49. DOI: 10.3322/caac.21660 PMID: 33538338.

7. International Agency for Research on cancer. Nepal, Source Globocan. Available from2020 [cited 2021 May 09]. Available from: https://gco.iarc.fr/today/data/ factsheets / populations /524-nepal-fact-sheets.pdf. [Accessed on $9^{\text {th }}$ May 2021]

8. Ahnen DJ, Wade SW, Jones WF, Sifri R, Mendoza Silveiras J, Greenamyer J, et al. The increasing incidence of young-onset colorectal cancer: a call to action. Mayo Clin Proc. 2014;89(2):216-24. DOI: 10.1016/j. mayocp.2013.09.006 PMID: 24393412.

9. Sakamoto T, Matsuda T, Nakajima T, Saito Y. Clinicopathological features of colorectal polyps: evaluation of the 'predict, resect and discard' strategies. Colorectal Dis. 2013;15(6):e295-300. DOI: 10.1111/ codi.12210 PMID: 23527478.

10. Hamilton SR, Bosman FT, Boffetta P, Ilyas M, Morreau $\mathrm{H}$, Nakamura SI, et al. Tumors of colon and rectum. In: Bosman FT, Carneiro F, Hruban RH, Theise ND. Pathology and genetics of tumors of digestive system. 4th ed. Lyon: IARC press; 2010. p.131-82.

11. Protocol for the Examination of Specimens From Patients With Carcinoma of the Colon and Rectum [Internet]. [Place unknown]: College of American Pathologists; 2017 [cited 2020 July 22]. Available from: http://www.documents.cap.org/protocols/cap-colonrectum-2017-v4000.pdf

12. Johnston L, Carey F. Pathology of colorectal polyps and cancer. Surgery (Oxford). 2020;38(1):12-17. Available from: https://doi.org/10.1016/j.mpsur.2019.10.012

13. Kefeli A, Basyigit S, Yeniova AO, Nazligul Y, Kucukazman M, Aktas B. General Properties of Colon Polyps in Central Anatolia. Euroasian J Hepatogastroenterol. 2014;4(1):7-10.DOI:10.5005/jp-journals-10018-1088 PMID: 29264311.

14. Shah S, Shrestha S, Shah JN, Paudyal S. Clinicopathological characteristics of colorectal carcinoma at university teaching hospital, Nepal. Journal of Patan Academy of Health Sciences. 2014;1(2):35-8. DOI: 10.3126/jpahs.v1i2.16644

15. Shrestha G, Khanal S, Mulmi R, Sapkota G. Five-year trend of colorectal cancer incidence in B.P. Koirala Memorial Cancer Hospital of Central Nepal: a crosssectional study. IJS Global Health. 2020;3(6):e30. DOI:10.1097/GH9.0000000000000030

16. Ibrahim KO, Anjorin AS, Afolayan AE, Badmos KB. Morphology of colorectal carcinoma among Nigerians: a 30-year review. Niger J Clin Pract. 2011;14(4):432-5. DOI: 10.4103/1119-3077.91750 PMID: 22248944.

17. Hong TS, Clark JW, Haigis KM. Cancers of the Colon and Rectum: Identical or Fraternal Twins? Cancer Discovery. 2012;2(2):117-21. DOI: 10.1158/21598290 PMID: 22585856.

18. Rawal S, Laudari U, Thapa A, Jha M, Shrestha D, Maharjan $\mathrm{M}$, et al. Colorectal Cancer in Young Age Group: Where Do We Stand? Nepal Med Coll J. 2019;21:104-9. DOI: 10.3126/nmcj.v21i2.25108

19. Kansakar P, Singh Y. Changing Trends of Colorectal Carcinoma in Nepalese Young Adults. Asian Pac J Cancer Prev. 2012;13(7):3209-12. DOI: 10.7314/ APJCP.2012.13.7.3209 PMID: 22994735.

20. Takeuchi K, Kuwano H, Tsuzuki Y, Ando T, Sekihara M, Hara T, et al. Clinicopathological characteristics of poorly differentiated adenocarcinoma of the colon and rectum. Hepatogastroenterology. 2004;51(60):1698702 .

21. Moghimi-Dehkordi B, Safaee A, Zali MR. Comparison of colorectal and gastric cancer: survival and prognostic factors. Saudi J Gastroenterol. 2009;15(1):18-23. DOI: 10.4103/1319-3767.4328 PMID: 19568550.

22. Siegel R, DeSantis C, Virgo K, Stein K, Mariotto A, Smith $\mathrm{T}$, et al. Cancer treatment and survivorship statistics, 2012. CA Cancer J Clin. 2012;62(4):220-41. DOI: 10.3322/caac.21149 PMID: 22700443.

23. Luo C, Cen S, Ding G, Wu W. Mucinous colorectal adenocarcinoma: clinical pathology and treatment options. Cancer Commun. 2019;39(1):13. DOI: 10.1186/s40880-019-0361-0 PMID: 30922401. 
24. Pozos-Ochoa LI, Lino-Silva LS, Leon-Takahashi AM, Salcedo-Hernandez RA. Prognosis of Signet Ring Cell Carcinoma of the Colon and Rectum and their Distinction of Mucinous Adenocarcinoma with Signet Ring Cells. A Comparative Study. Pathol Oncol Res. 2018;24(3):609-16. DOI: 10.1007/s12253-0170283-6 PMID: 28785968.

25. Venugopal A, Stoffel EM. Colorectal Cancer in Young
Adults. Current treatment options in gastroenterology. 2019;17(1):89-98. DOI: 10.1007/s11938-01900219-4 PMID: 30712157.

26. Poudyal NS, Chaudhary S, Basnet BK, Paudel BN, Shrestha B, Mandal AK, et al. Colorectal Cancer in Different Age Groups in a Tertiary Hospital in Nepal. JNMA J Nepal Med Assoc. 2017;56(206):203-6. DOI: 10.31729/jnma.3113 